\title{
All-optical switching based on optical fibre long period gratings modified
} bacteriorhodopsin

\author{
S. Korposh ${ }^{1,2}$, S. James ${ }^{1}$. M. Partridge ${ }^{1}$, M. Sichka ${ }^{3}$, R. Tatam ${ }^{1}$ \\ ${ }^{1}$ Engineering Photonics, Cranfield University, Cranfield, Bedford MK43 OAL, UK \\ ${ }^{2}$ Optics and Photonics Group, Department of Electrical and Electronic Engineering, The University of \\ Nottingham, Nottingham, NG7 2RD, UK \\ ${ }^{3}$ Institute of Solid-State Physics \& Chemistry, Uzhgorod National University, Voloshina St 54, \\ Uzhgorod 88000, Ukraine
}

\begin{abstract}
All-optical switching using an optical fibre long-period gating (LPG) modified with bacteriorhodopsin (bR) is demonstrated. The switching process is based on the photo-induced RI change of bR, which in turn changes the phase matching conditions of the mode coupling by the LPG, leading to modulation of the propagating light. The effect was studied with an LPG immersed into a bR solution and with LPGs coated with the bR films, deposited onto the LPGs using the layer-by-layer electrostatic self-assembly (LbL) method. The dependence of the all-optical switching efficiency upon the concentration of the bR solution and on the grating period of the LPG was also studied. In addition, an in-fibre Mach-Zehnder interferometer (MZI) composed of a cascaded LPG pair separated by $30 \mathrm{~mm}$ and modified with bR was used to enhance the wavelength range of all-optical switching. The switching wavelength is determined by the grating period of the LPG. Switching efficiencies of $16 \%$ and $35 \%$ were observed when an LPG and an MZI were immersed into bR solutions, respectively. The switching time for devices coated with bR-films was within 1s, 10 times faster than that observed for devices immersed into bR solution.
\end{abstract}

Keywords: all-optical switching, bacteriorhodopsin (bR), optical fibre, Mach-Zehnder interferometer, long period gratings

\section{Introduction}

Growing demand for faster information processing in telecommunications and information processing technologies drives the interest in finding new methods and materials that allow operation in the alloptical domain, which has the potential to provide large bandwidth and allow the exploitation of the parallelism intrinsic to the optical approach, translating into high-processing speeds [1]. In all-optical switching, the information encoded in an optical signal is controlled and/or modulated by another optical signal via the photo-induced refractive (RI) changes of the nonlinear optical materials [2]. All-optical switching has attracted a lot of research attention, with the aim of creating novel flexible optical circuits [3, 4], light emission [5, 6] and Q-switching in all-fibre lasers [7]. For all-optical switching in all-fibre lasers, the nonlinear properties of the optical fibre are employed, requiring high power ultrashort lasers 
[8]. Lu et al. demonstrated an all-fibre passively Q-switched Yb-doped laser using a piece of Sm-doped

fibre as a saturable absorber [9]. All-optical switching based on organic materials promises numerous advantages such as higher bandwidth, speed and compactness over their inorganic semiconductor based counterparts [2].

Bacteriorhodopsin (bR) is a photochromic retinal-protein found in the bacterium Halobacterium salinarum. It exists in the form of a two-dimensional crystal incorporated into the bacterium cell membranes, which are called the purple membranes $(\mathrm{pm})$ due to their intense purple colour. Absorption of light by the retinal-protein leads to a reversible colour change from purple to yellow due to protein conformational changes accompanied by a series of spectral changes of the protein, termed a photocycle. This process is characterized by displacements of the optical absorption bands [10], as demonstrated in Figure 1.
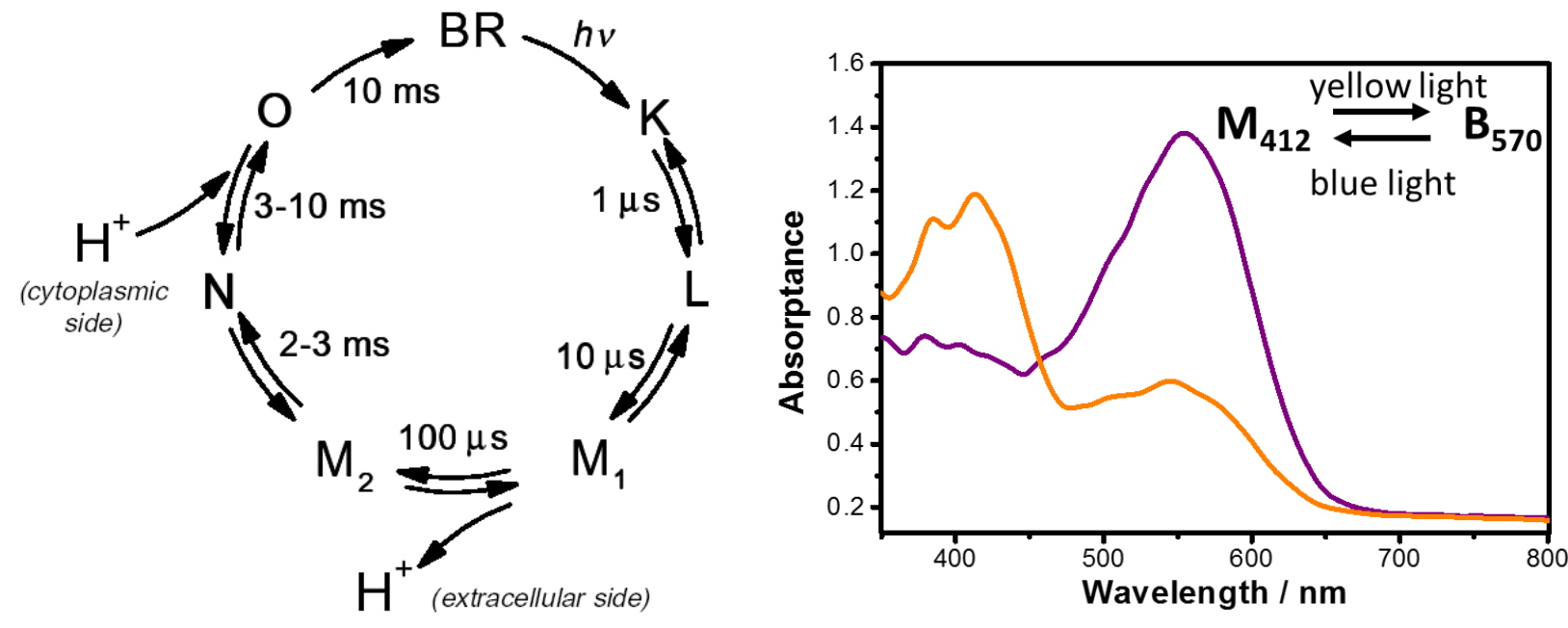

Figure 1: a, bacteriorhodopsin photocycle and photo-intermediates [11]; and b, absorption spectra of the $\mathrm{bR}_{570}$ in ground state and longest lived intermediate $\mathrm{M}_{412}$.

Due to its unique optical and photoelectrical properties, bR has attracted interest across a range of areas such as optical memories [11], sensors [12,13], reversible holographic media [14] and spatial light modulators [15]. In the past decade, bR has been studied for use in all-optical switching $[16,17,18]$.

The first successful all-optical integrated optical switching experiment exploiting bR was described in [19], using a grating-coupled planar waveguide. The speed of optical switching was characterized by a submicrosecond rate constant $\sim 0.8 \mu \mathrm{s}$, (instrument limited), while the corresponding refractive index change was nearly the same as that associated with the forward reaction, but with opposite sign $\left(-1.8 \times 10^{-}\right.$ ${ }^{3}$ ). Der et al. [20] demonstrated optical switching with bR combined with an integrated optical MachZehnder interferometer, with a higher than $90 \%$ efficiency due to the M-stat. It was also shown that the 
refractive index change of the K-state $\left(9 \times 10^{-4}\right)$ is high enough for fast switching as the life time of this intermediate is much shorter than that of the $\mathrm{M}$ intermediate [20]. This principle was later implemented in high-speed integrated optical logic gates [21], where the use of an ultrafast transition of the bR photocycle (BR-K), allowed high-speed (nanosecond) logical switching to be achieved Subpicosecond photonic switch was achieved using $b R$, via its ultrafast $B R>K$ and $B R>I$ transitions, which is fastest switching time reported so far for bR protein [22]. This ultrafast switching was achieved in so-called "frequency switching" mode, where one can select different frequency bands of very narrow bandwidth $(\Delta \lambda<1 \mathrm{~nm})$ of a broadband pulse, enabling frequency demultiplexing, an essential operation in optical information processing [22].

A number of schemes demonstrating all-optical switching, based on mirrorless free space optics [7], an integrated optic Mach-Zender interferometer (MZI) [9] and recently on a high-Q micro-resonator cavity [8], have been reported. The longest absorption wavelength of the bR intermediate is $640 \mathrm{~nm}$ for $\mathrm{O}_{640}$ (Figure 1) and thus most of the all-optical switching was demonstrated in the visual range. It was recently shown that a micro-resonator cavity modified with an electrostatically self-assembled bR-based thin film can perform all-optical switching in the telecommunication bands at $1311 \mathrm{~nm}$ and $1550 \mathrm{~nm}$ [17]. Fábián et al. demonstrated fast picosecond all-optical switching using an integrated optic MZI, one channel of which was modified with bR [9]. Another attractive feature of bR-based optical components is an ability to tailor the photoresponse of bR-protein using various methods including mutation [23], quantum dots [24], nanoparticles [25], chemical additives [26] and doping bR in matrices [23, 12]. These manipulations allow to control and tailor life-time of intermediates and hence switching time of the of the bR based optical component.

In this work, an optical fibre long period grating (LPG) was used for the first time as a platform to demonstrate all-optical in-fibre switching, with $\mathrm{bR}$ as the switching material. An advantage of the use of LPGs is that the switching wavelength is determined by the grating period of the LPG and thus it can be tailored by choosing the appropriate grating period. In addition, an all-in fibre MZI composed of a cascaded LPG pair separated by $30 \mathrm{~mm}$ and modified with $\mathrm{bR}$ was used to enhance the wavelength range of all-optical switching.

\section{Experimental}

\subsection{Materials}

Bacteriorhodopsin was extracted as purple membrane fragments (pmf) from Halobacterium salinarum, strain S9, cultured in the laboratory at Uzhgorod National University according to standard procedures $[27,28]$. The typical diameter of these fragments was $500 \mathrm{~nm}$. Poly(diallyldimethylammonium chloride) (PDDA, Mw: 200,000-350,000, $20 \mathrm{wt} \%$ in $\mathrm{H}_{2} \mathrm{O}$ ), sodium chloride, sodium hydroxide, hexane were 
purchased from Sigma-Aldrich. All of these chemicals were guaranteed reagents, and used without further purification. Deionized pure water $(18.3 \mathrm{M} \Omega \cdot \mathrm{cm})$ was obtained by reverse osmosis followed by ion exchange and filtration (Millipore, Direct-QTM).

\subsection{Optical fibre LPGs}

An LPG is a period modulation of the properties of an optical fibre that promotes the coupling of light between core and cladding modes. Typically, the transmission spectrum of an LPG contains a number of resonance bands, each corresponding to coupling to a different cladding mode and each showing a different sensitivity to environmental perturbation, which has been noted to offer the potential for multiparameter sensing. The wavelengths at which light is coupled from the core to the cladding modes is governed by the phase matching equation

$$
\lambda_{x}=\left(n_{\text {core }}-n_{\text {clad }(x)}\right) \Lambda
$$

where $\lambda_{x}$ represents the wavelength at which light is coupled to the $\mathrm{LP}_{0 \mathrm{x}}$ cladding mode, $n_{\text {core }}$ is the effective refractive index of the mode propagating in the core of the fibre, $n_{\operatorname{clad}(x)}$ is the effective index of the $\mathrm{LP}_{0 \mathrm{x}}$ cladding mode and $\Lambda$ is the period of the LPG. The dispersion of an optical fibre is such that the difference between the core and cladding mode effective indices exhibits a turning point where the value is maximum. For an LPG fabricated with a period such that equation (1) is satisfied at the phase matching turning point (PMTP), it has been shown that the sensitivity of the transmission spectrum to perturbation is at its maximum, and that for subsequent decreases in $\left(\mathrm{n}_{\text {core }}-\mathrm{n}_{\text {clad }(\mathrm{x})}\right)$, the LPGs transmission spectrum is characterised by the formation of a broad resonance band that subsequently splits into two.

A key feature of LPGs that makes them suited for use as a platform for all optical switching is their inherent sensitivity to the refractive index (RI) of the medium surrounding the fibre. This is a result of the dependence of the phase matching condition upon the effective index of the cladding mode. This has been exploited widely to demonstrate LPG based refractometers [29], and to investigate the use of LPGs as species specific chemical sensors via the deposition of thin films of materials that displayed an analyte induced refractive index change [29, 30, 31, 32].

The formation of an intrinsic fibre optic Mach-Zehnder interferometer (MZI) by cascading two identical long period LPGs has been shown to produce a sinusoidal channelled spectrum within the attenuation bands that characterize the transmission spectrum of an LPG, as illustrated in Figure 1 [33].

The phase of the channelled spectrum is dependent on the difference in the optical path lengths of the light propagating in the core and cladding modes, according to:

$$
\varphi=\frac{2 \pi}{\lambda}\left(n_{\text {core }}-n_{\operatorname{clad}(x)}\right) L
$$


where $\lambda$ represents the wavelength, and $\mathrm{L}$ is the centre-to-centre distance between two gratings.

2 Perturbation of the section of optical fibre separating the LPGs results in a change in the phase of the channelled spectrum within the resonance band envelope.

4

$5 \quad$ LPGs with a periods of 110.9 and $111 \mu \mathrm{m}$, each of length $35 \mathrm{~mm}$, were fabricated in a photosensitive single mode optical fibre (Fibercore PM750) with a cut-off wavelength of $670 \mathrm{~nm}$ using point by point exposure to the output from a UV laser source (frequency quadrupled Nd:YAG laser operating at a wavelength of $266 \mathrm{~nm}$ ) [34]. The grating periods were selected such that the LPGs operated at the phase matching turning point $(110.9 \mathrm{~nm})$ and further from the turning point, where attenuation bands are split $(111 \mu \mathrm{m})$. Operating near the turning point ensures optimised sensitivity [35]. To form the in-fibre MachZender interferometer (MZI), a pair of LPGs of grating period $110.3 \mu \mathrm{m}$, each of length $35 \mathrm{~mm}$ and separated by $30 \mathrm{~mm}$, was fabricated in the same way, Figure 2. The transmission spectra (TS) of the LPG and of the in-fibre MZI were recorded by coupling the output from a tungsten-halogen lamp (Ocean Optics HL-2000) into the fibre, and by analysing the transmitted light using a fibre coupled CCD spectrometer (Ocean Optics HR4000).

16

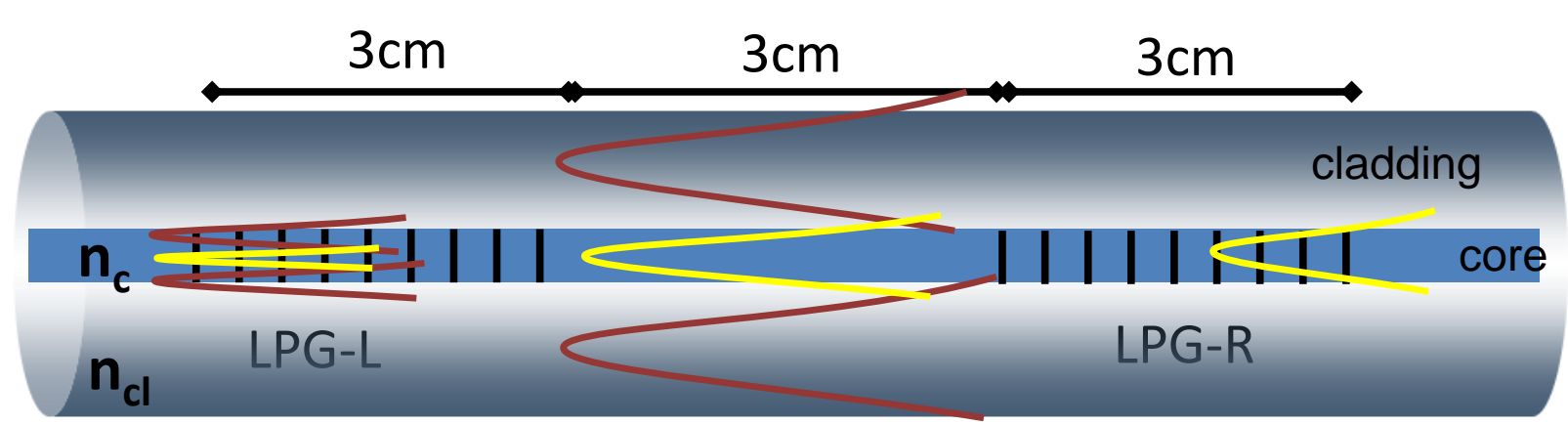

\section{Core mode}
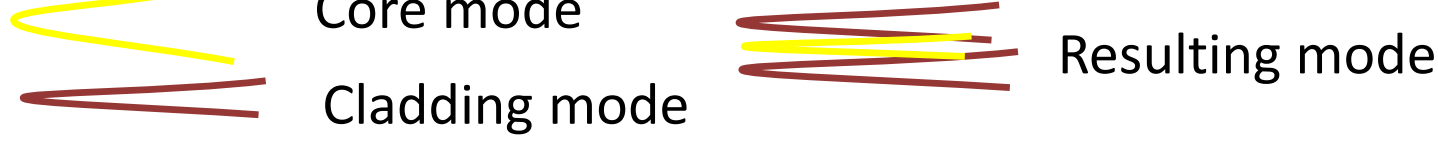


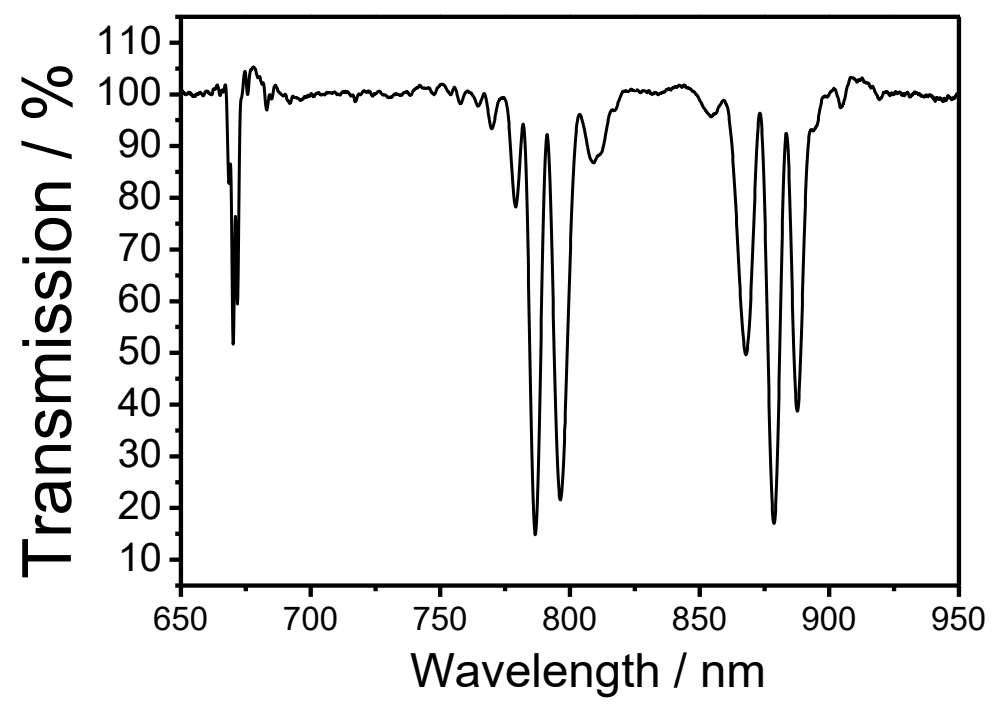

(b)

Figure 2. (a), Schematic of diagram of a cascaded LPG Mach Zehnder interferometer; and (b), the TS of an MZI formed between a pair of cascaded LPGs of length $\mathrm{L}=30 \mathrm{~mm}$, separated by $\mathrm{L}=30 \mathrm{~mm}$, with $110.3 \mu \mathrm{m}$ grating period.

\section{3. bR film preparation}

Two methods were used to deposit bR films onto the optical fibre: casting and layer-by-layer (LbL) electrostatic self-assembly.

\subsubsection{LbL deposition}

LbL deposition involved the sequential deposition of a polycation material, PDDA, which has a positive charge, and bR membranes, which have negative charge. The LPG was fixed in a Teflon holder that contained a compartment to accommodate the solution [6]. The region of the optical fibre containing the LPG was rinsed in with deionised water and immersed into $1 \mathrm{wt} \%$ ethanolic $\mathrm{KOH}$ (ethanol/water $=3: 2$, v/v) for 20 minutes, leading to a negatively charged surface. The optical fibre was then immersed sequentially into a solution containing positively charged polymer PDDA $(0.5 \mathrm{wt} \%$, pH=7, with $0.5 \mathrm{M}$ $\mathrm{NaCl})$ and into a bR solution $(0.5 \mathrm{mg} / \mathrm{mL}, \mathrm{pH}=9.4$ adjusted by $\mathrm{NaOH})$, each for 10 minutes, so that alternate layers of PDDA and bR were deposited onto the surface of the fibre, Figure 3 [36]. The fibre was rinsed in distilled water and dried by flushing with nitrogen gas after each deposition step. This process was repeated until a 12 cycles-thick $(\mathrm{PDDA} / \mathrm{bR})_{12}$ film was deposited onto the LPG. The TS was recorded after each deposition step. 
(a)

LPG fibre
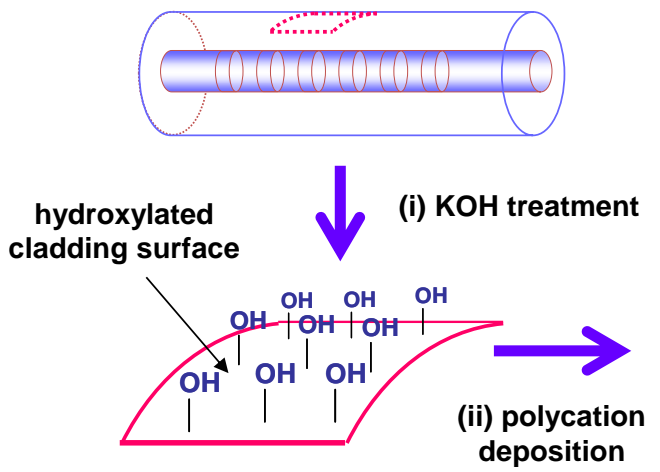

PDDA (0.5 w\%

in water) (b)
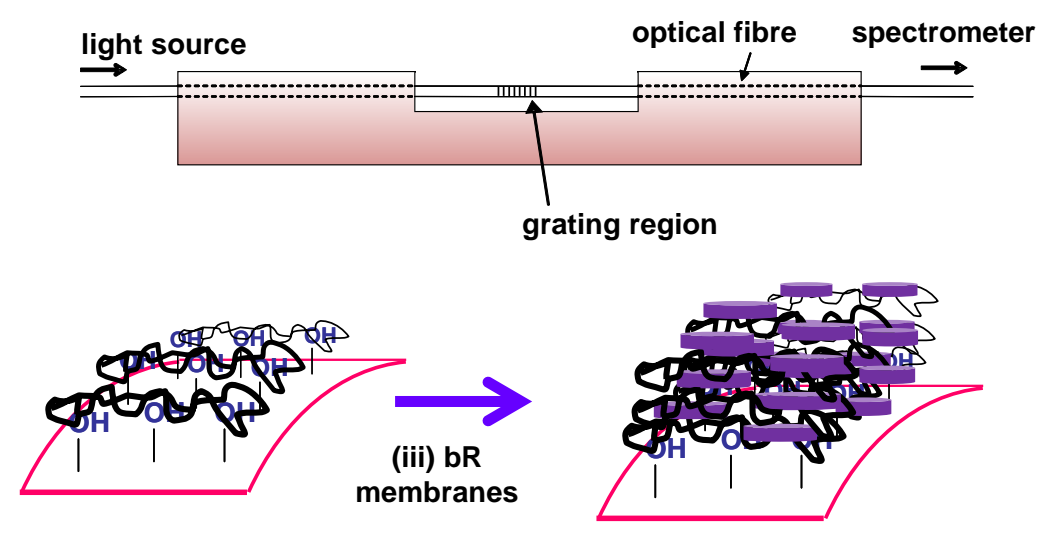

Figure 3. (a), Schematic illustration of the LbL method used for bR film deposition; and (b), Teflon made fibre holder with compartment that was used to accommodate solution.

\subsubsection{Casting}

When depositing bR onto an LPG, the section of fibre containing the LPG was immersed into a bR aqueous solution $(12 \mathrm{mg} / \mathrm{mL})$ for $30 \mathrm{~min}$ and then dried using nitrogen gas to form a self-assembled dry thin film of bR. To deposit a bR film on the surface of the fibre separating the cascaded LPGs in the MZI, the $30 \mathrm{~mm}$ long section separating the LPG pair was immersed into a bR aqueous solution (12 $\mathrm{mg} / \mathrm{mL}$ ) for $30 \mathrm{~min}$ and then dried using nitrogen gas.

\subsection{Optical switching}

A cw frequency doubled Nd:YAG laser $(532 \mathrm{~nm}$, Coherent (California, USA) DPSS $532 \mathrm{~nm} 140$ laser with a mean power of $160 \mathrm{~mW}, 40 \mathrm{~mW} / \mathrm{cm}^{2}$ once directed onto the fibre) was used as the actinic light source. A beam expander was used to allow the illumination of entire length of the LPG, or, in the case of the cascaded LPG, of the section of fibre separating the LPGs. The influence of the actinic light source on the TS of an LPG immersed into a bR solution (12 mg/ML or $0.5 \mathrm{mg} / \mathrm{mL})$ and that of on bR filmmodified optical fibre LPGs was studied. Figure 4 shows the experimental arrangement used to characterise the response of an unmodified LPG to the refractive index change of a bR solution. For the coated LPGs, the same system was employed, but the well in the Teflon holder did not contain any liquid. 


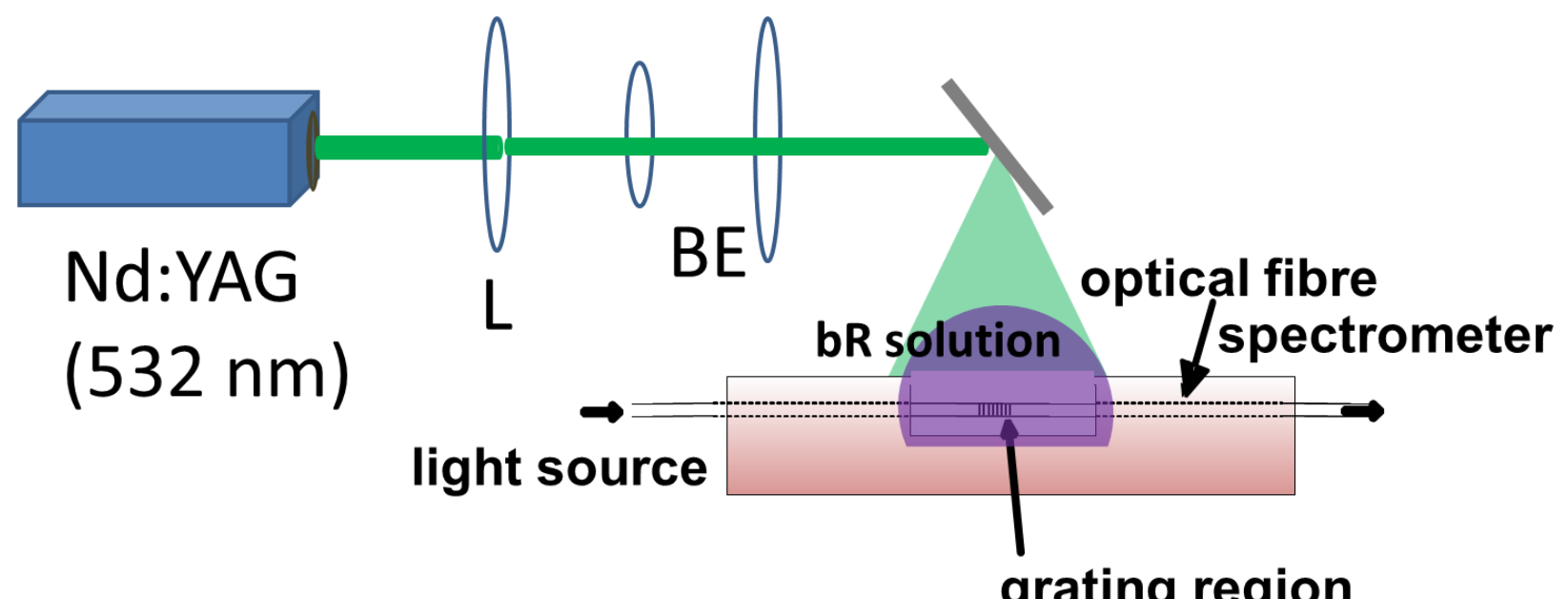

Figure 4. Schematic illustration of the set-up used for the all-optical switching; L, lens; BE, beam expander.

All measurements were conducted at room temperature and the effect of fluctuation in the temperature was observed.

The LPG acts as a refractometer, allowing the RI of the medium surrounding the LPG to be determined [37]. Using this approach, the actinic light- induced RI change of the bR film or of the bR solution was determined from the wavelength shift of the resonance band of the LPG. The response of the LPG sensor to RI change was calibrated using glucose solutions of known concentrations, similarly to previously reported work [31].

\section{Results and discussion}

\subsection{All-optical switching in bR solutions}

3.1.1 LPG

Figure 5 shows the TS of an LPG with a grating period of $111 \mu \mathrm{m}$ measured in a bR solution $(12 \mathrm{mg} / \mathrm{mL})$ before and after exposure to actinic light $(532 \mathrm{~nm})$. The period of the LPG was chosen such that sensor operated at phase matching turning point, where $2^{\text {nd }}$ attenuation band (centred at $840 \mathrm{~nm}$ ), corresponding to the coupling light from the core mode to $\mathrm{LP}_{021}$, is well developed [30]. The change of the RI of the bR solution induced by the actinic light led to an increase of the attenuation (12\%) at $840 \mathrm{~nm}$ and caused a $0.7 \mathrm{~nm}$ blue wavelength shift of the $1^{\text {st }}$ attenuation band (centred at $680 \mathrm{~nm}$ ) that corresponded to the coupling to LP 019 , Figure 5. This behaviour of the LPG TS is typical for an increase in the RI of the surrounding medium [31]. It should be noted that when the TS of the LPG was measured during exposure to the actinic light and while immersed in pure water, no measurable changes in the TS were observed, Figure S1. Figure 5b shows the difference TS obtained by subtracting the TS measured before exposure from that measured at the saturation point (ca. 2 min after actinic light was switched ON) of the exposure 
1 to the actinic light from that. Using the calibration curve shown in Figure S2, the photo-induced change

2 of the RI of the bR solution was determined to be ca. $0.023 \pm 0.001$ and $0.007 \pm 0.00001$ when measured

3 at $840 \mathrm{~nm}$ and at $683 \mathrm{~nm}$, respectively, as shown in Figure 5d. The difference in the photo-induced

4 change of the RI of the bR solution at $840 \mathrm{~nm}$ and $683 \mathrm{~nm}$, Figure $5 \mathrm{~d}$, is caused by distribution of the

5 intensity-dependent steady-state population between the B state and, intermediates $\mathrm{M}, \mathrm{N}$, and $\mathrm{O}$ of the

6 photocycle [23]. These results correlate well with previous reports of the spectral dependence of the

7 photo-induced RI change of bR films [11].

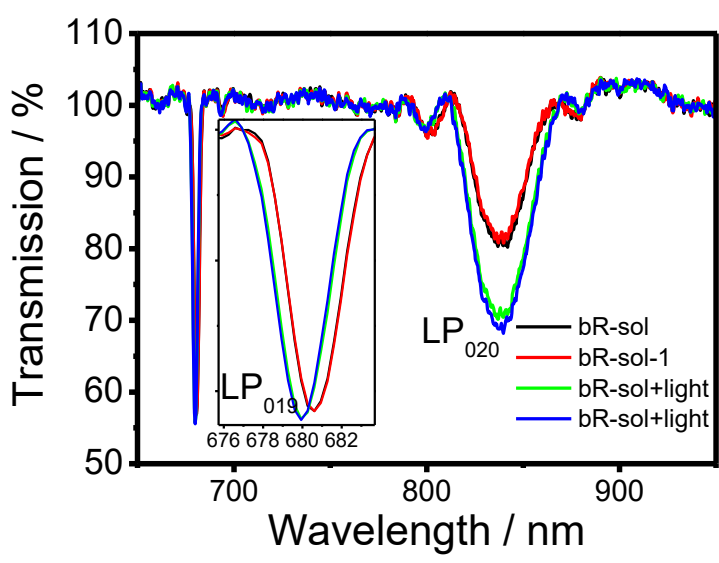

(a)

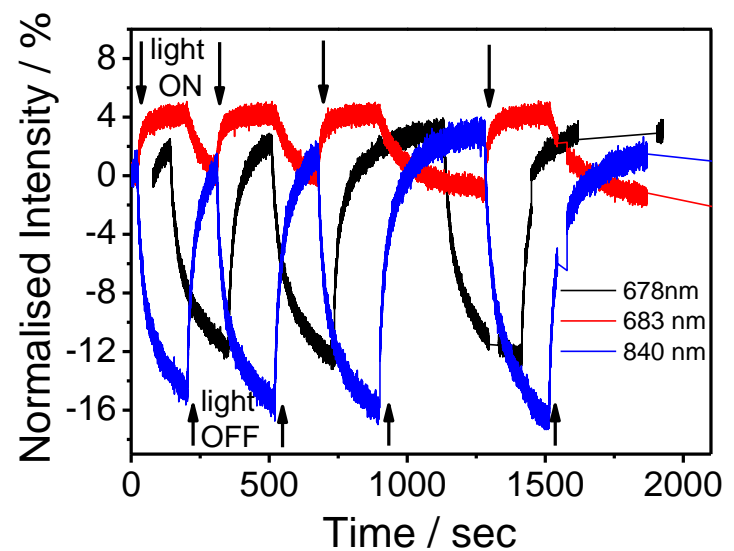

(c)

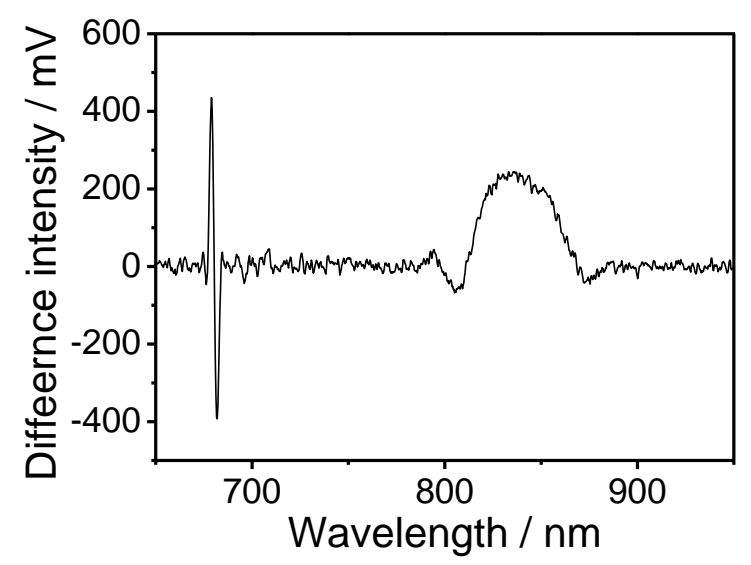

(b)

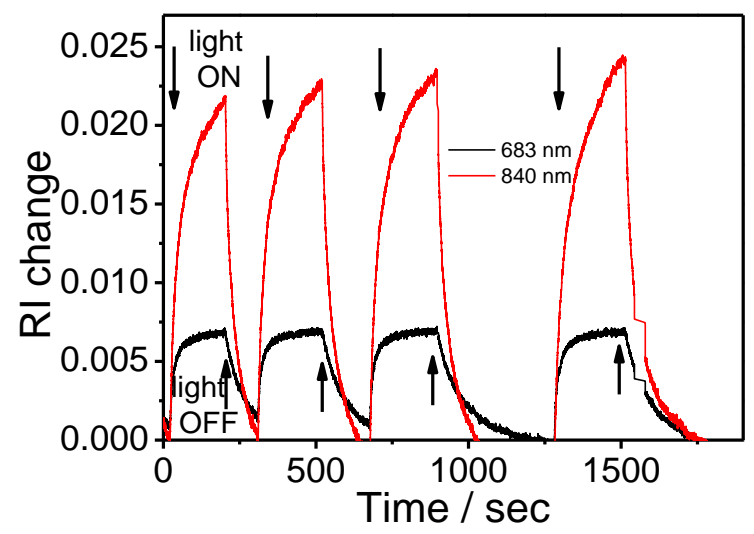

(d)

Figure 5. (a), Evolution of the TS of the LPG $(\Lambda=111 \mathrm{~mm})$ measured in bR solution $(12 \mathrm{mg} / \mathrm{mL})$ when actinic light was switched on and off; (b), difference TS (obtained by subtracting the TS measured before exposure to the actinic light from that measured after the saturation point during exposure to the actinic light) and (c), and (d), Dynamic change of the normalised sensor response and calculated RI, respectively measured at 683 and $840 \mathrm{~nm}$.

The TS exhibited similar behaviour when measured with the LPG in a bR solution of concentration 0.5 $\mathrm{mg} / \mathrm{mL}$, Figure S3. However, the magnitude of the change was significantly reduced from that observed 
1 in the $12 \mathrm{mg} / \mathrm{mL}$ bR solution, as shown in Figure 6. These results suggest that efficiency of the optical 2 switching depends upon the concentration of photorefractive material.
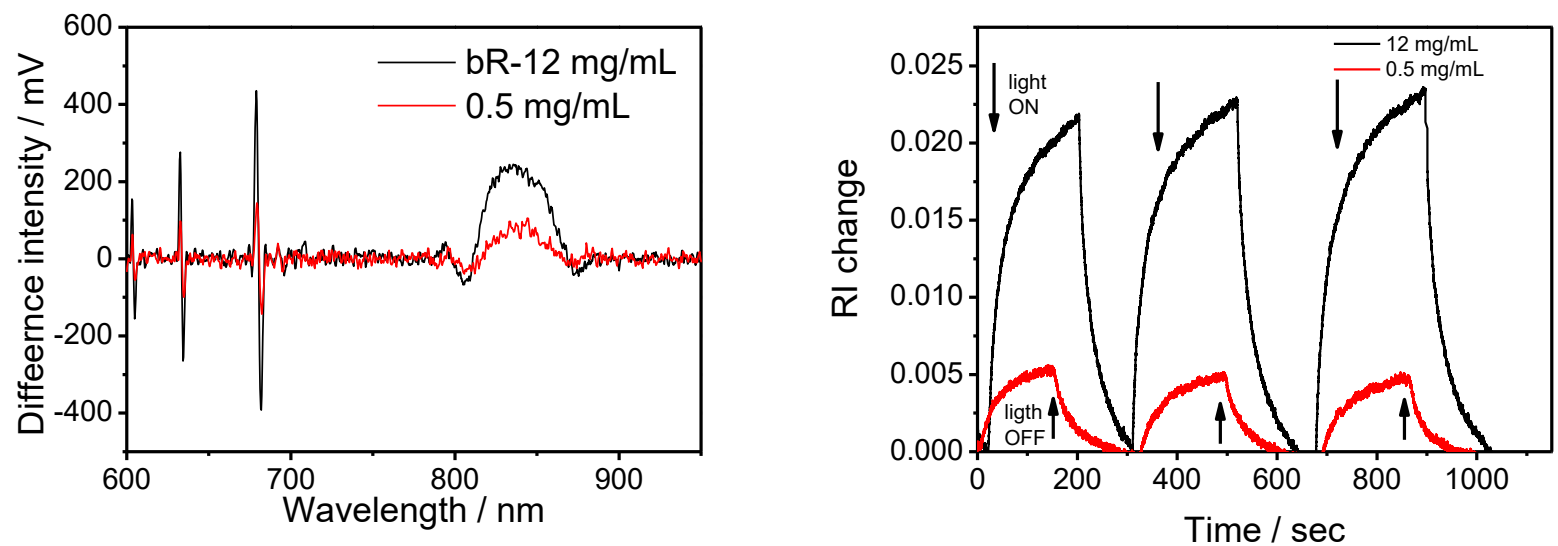

3

4 Figure 6. Comparison of (a), the difference TS (obtained by subtracting the TS measured before

exposure to the actinic light from that measured after the saturation point during exposure to the actinic

light) and (b), the dynamic intensity change measured at $840 \mathrm{~nm}$, for bR concentration of: black line, 12 $\mathrm{mg} / \mathrm{mL}$; and red line, $0.5 \mathrm{mg} / \mathrm{mL}$.

Similar results were obtained when an LPG with grating period of $110.9 \mu \mathrm{m}$ was employed; at this grating period the $2^{\text {nd }}$ attenuation band is split into dual resonance bands, with minima at 796 and 874 $\mathrm{nm}$, allowing optical switching to be observed simultaneously at different wavelengths, Figure 7. Using the calibration curve shown in Figure S4. The photo-induced RI changes of the bR solution $(12 \mathrm{mg} / \mathrm{mL})$ were found to be $0.018,0.016$ and 0.09 at 670,796 and $874 \mathrm{~nm}$, respectively. 


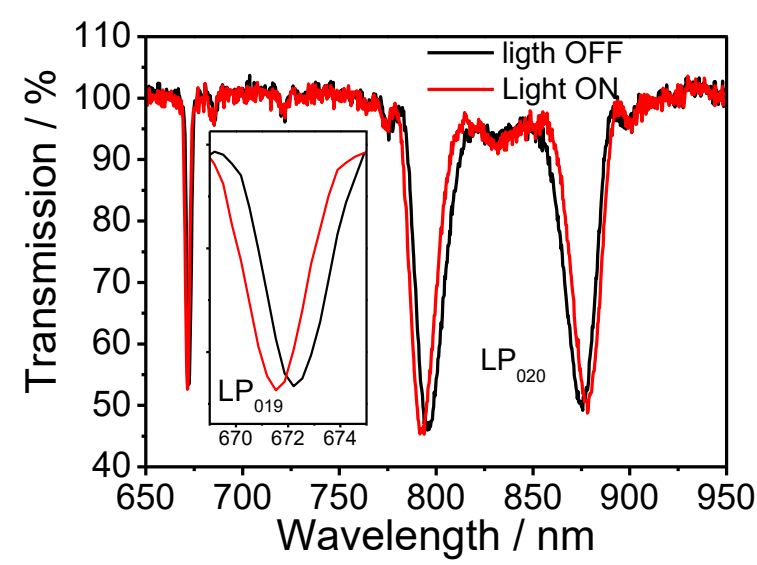

(a)

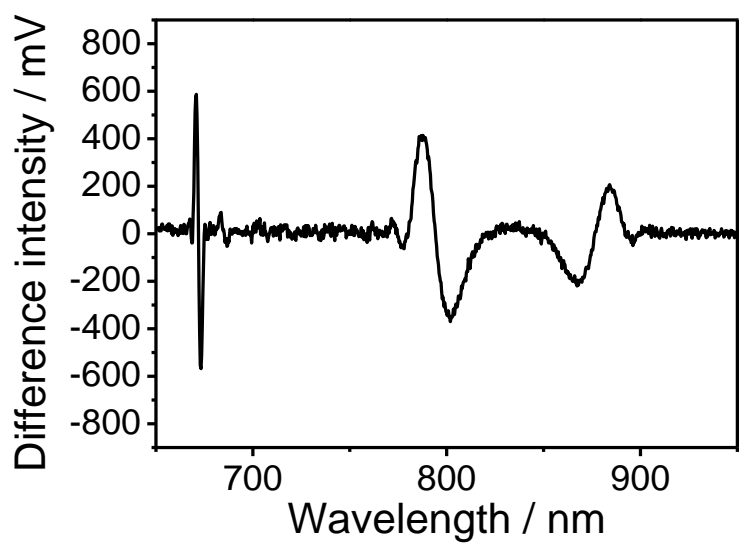

(b)

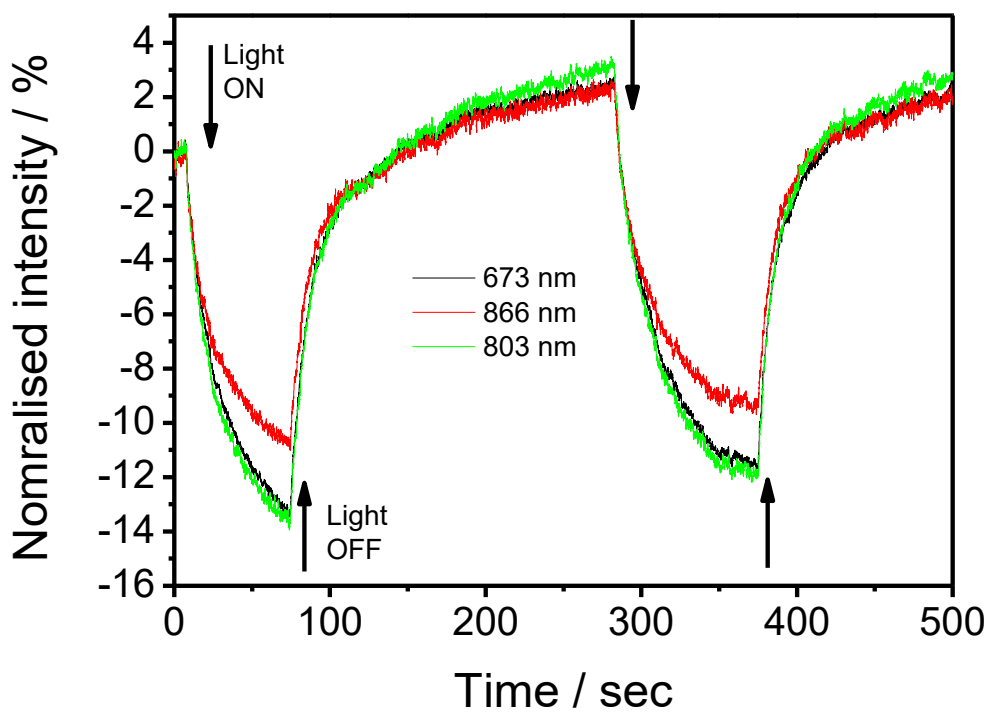

(c)

Figure 7. (a), Evolution of the TS of the LPG $(\Lambda=110.9 \mathrm{~mm})$ measured in bR solution $(12 \mathrm{mg} / \mathrm{mL})$ when actinic light was switched on and off; (c), difference TS (obtained by subtracting the TS measured before exposure to the actinic light from that measured after the saturation point during exposure to the actinic light) and (c), dynamic intensity change measured at: black line, $673 \mathrm{~nm}$; red line, $866 \mathrm{~nm}$; and green line, $803 \mathrm{~nm}$.

\subsection{2. $M Z I$}

Figure 8 shows TS of the MZI measured when the section of optical fibre separating the LPG pair was immersed in the bR solution $(12 \mathrm{mg} / \mathrm{mL})$, before and during exposure to actinic light. The wavelength shift was ca. $1 \mathrm{~nm}$ across all spectral features in the channelled spectrum of the MZI, associated with the phase change of the interference. The efficiency of the all-optical switching in MZI was ca. $35 \%$, which is ca. 2.2 times larger as compared with single LPG, Figure 7c. In addition, photo-induced RI changes 
can be measured at 9 different wavelengths, providing richer spectral information and offering potential for the development of logic devices [16].

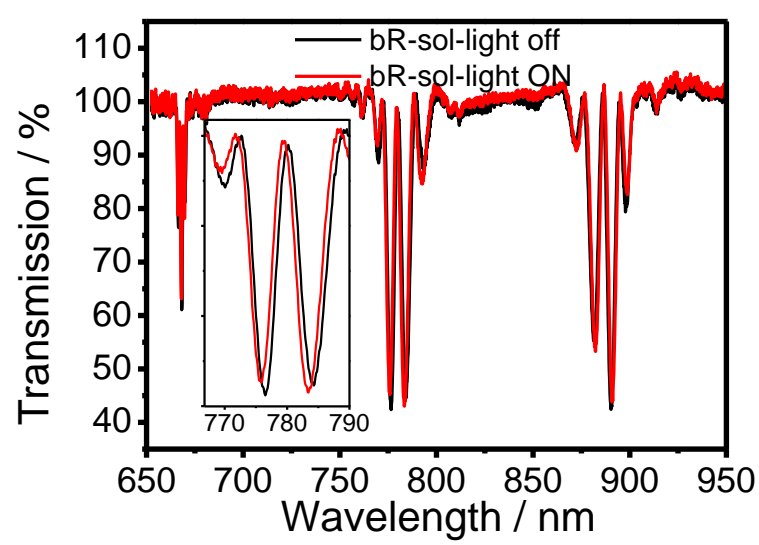

(a)

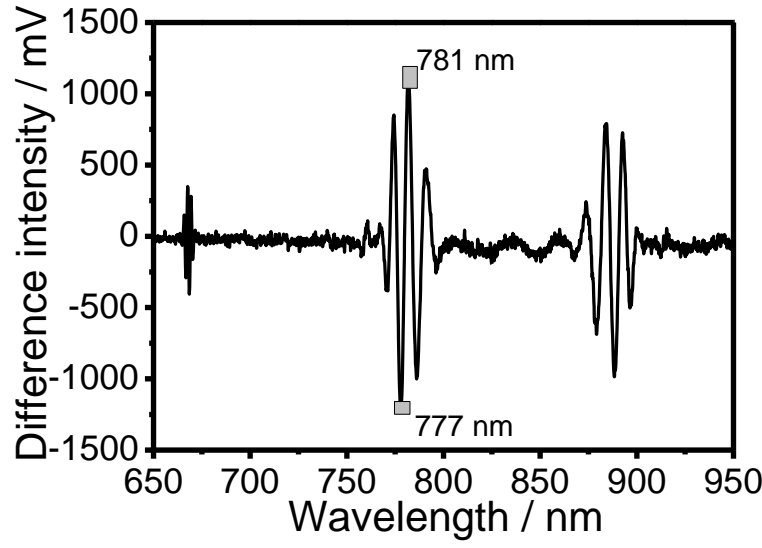

(b)

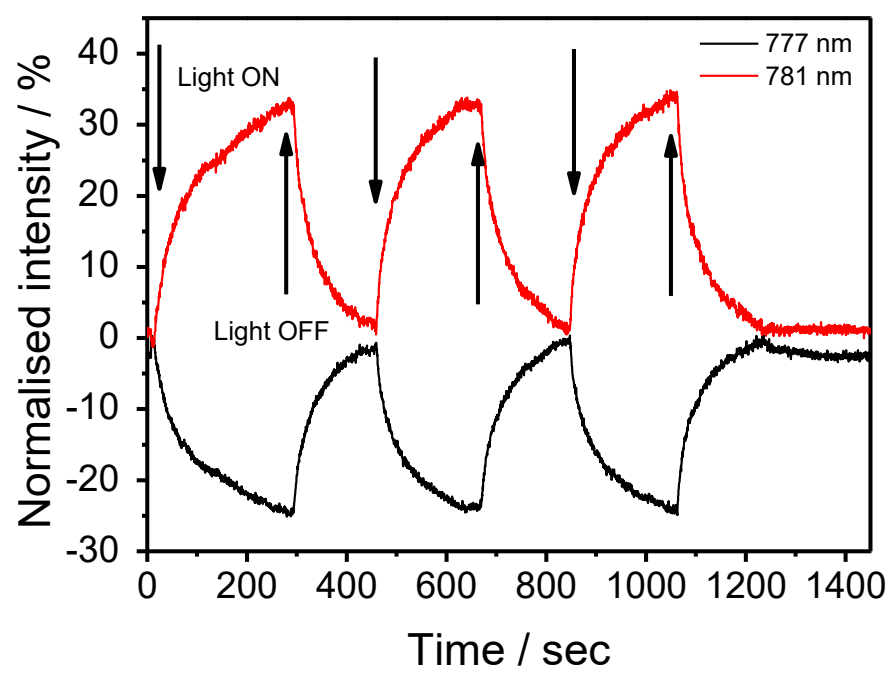

(c)

Figure 8. (a), TS of the MZI formed by the LPG pair $(\Lambda=110.3 \mathrm{~mm}$, separation $30 \mathrm{~mm})$ measured in bR solution (12 mg/mL): black line, before and red line, after actinic light exposure; (b), difference TS (obtained by subtracting the TS measured before exposure to the actinic light from that measured after the saturation point during exposure to the actinic light) and (c), dynamic intensity change measured at: black line, $777 \mathrm{~nm}$; and red line, $781 \mathrm{~nm}$.

The response and recovery times for all devices were within 10 s seconds, which was limited by the lifetime of the bR intermediates. In this case, the lifetime depended on the CW nature of the actinic light source [11], but also was due, in part, to the high concentration of water molecules in the bR purple membrane surrounding medium. It is known that in dry form the life-time of the bR intermediates shortens considerably [28]. 

3.2.1. $L b L$

3 Figure 9 (a) and (b) show evolution of the TS of an LPG of period $110.9 \mu \mathrm{m}$, measured with the fibre in 4 air and when immersed into the bR solution during the deposition of the PDDA/bR thin films. A linear 5 blue shift of the $1^{\text {st }}$ resonance $(0.077 \mathrm{~nm} /$ layer $)$ band was observed as the film thickness increased, 6 (figures 9 (c) and (d)) while the $2^{\text {nd }}$ resonance band was observed to split into two, with the central 7 wavelength of the split bands also showing two a linear dependence on the number of layers of the 8 PDDA/bR coating (Figures 9d). The linear wavelength shift suggests a uniform increase in the 9 PDDA/bR film thickness on each deposition cycle. The TS behaviour is typical of that observed when the thickness of a coating deposited onto an LPG is increased [35].

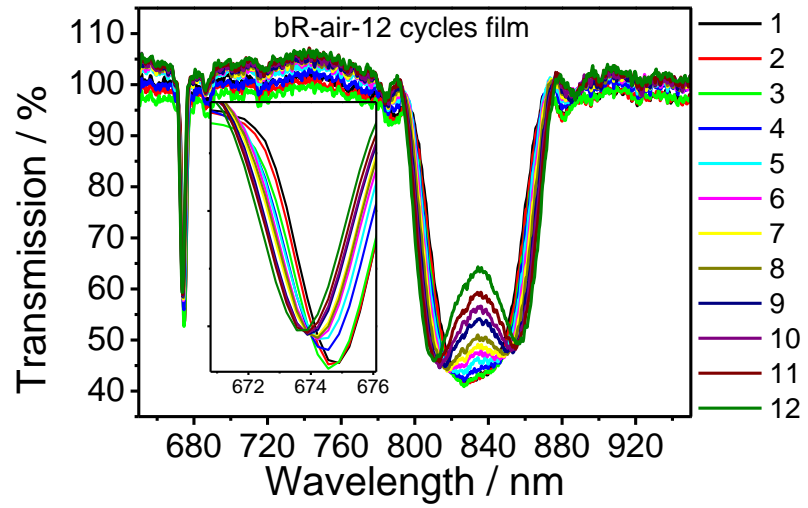

(a)

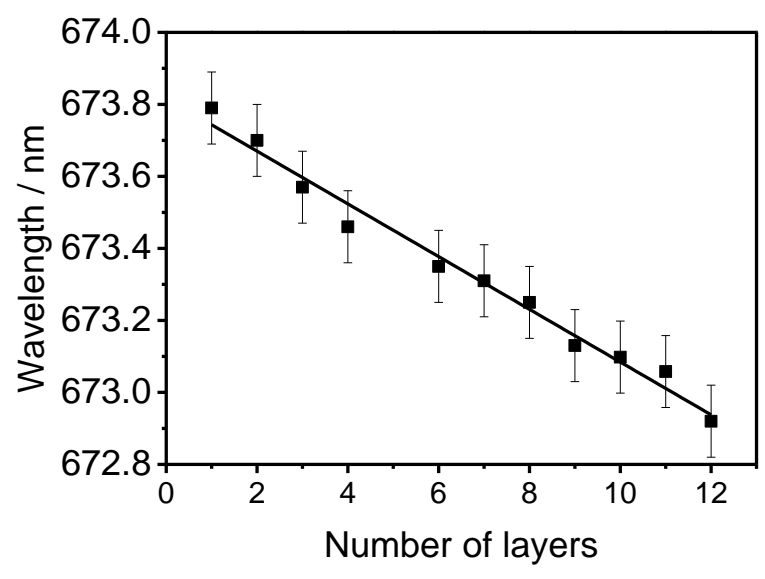

(c)

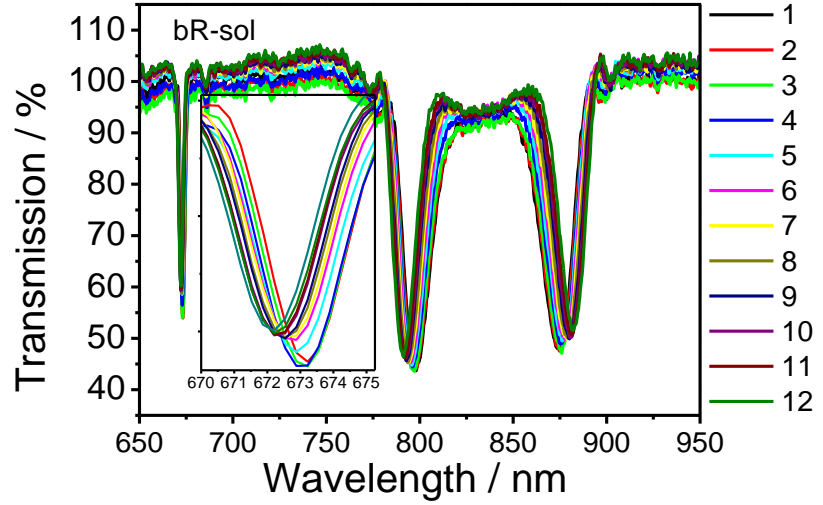

(b)

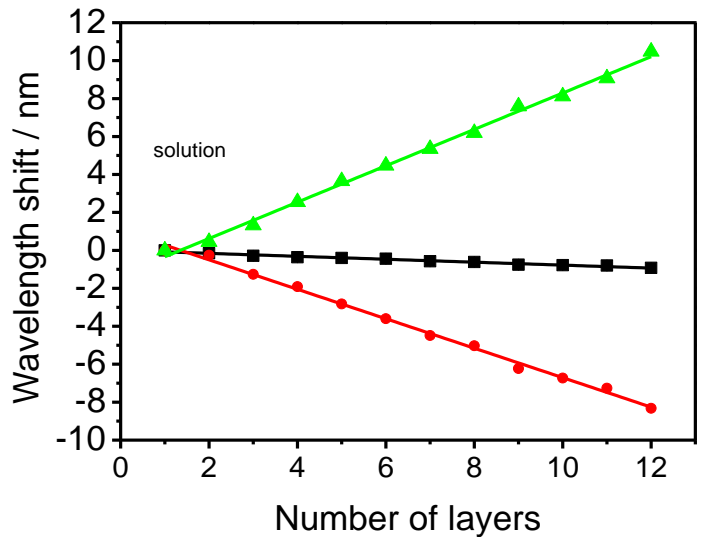

(d)

Figure 9. Evolution of the TS of an LPG of period $\Lambda=110.9 \mu \mathrm{m}$ during the deposition of the $(\mathrm{bR} / \mathrm{PDDA})_{12}$ film, measured after each deposition process step with the LPG in (a), air and (b), bR solution; Wavelength shifts of the attenuation bands plotted against the number of deposited layers; (c), in air for the band centred originally at 673 and (d), in bR solution; for the bands originally centred at $673 \mathrm{~nm}$ (squares), $800 \mathrm{~nm}$ (circles) and $860 \mathrm{~nm}$ (triangles). 
2 A blue shift of the $1^{\text {st }}$ attenuation band, accompanied by a decrease in attenuation at $850 \mathrm{~nm}$ 3 corresponding to the development of the $2^{\text {nd }}$ band, was observed after LPG immersion into bR solution $4(12 \mathrm{mg} / \mathrm{mL})$ for $30 \mathrm{~min}$ and subsequent drying, suggesting the formation of the cast bR film, Figure 10. 5 The significant change in the transmission of the $1^{\text {st }}$ attenuation band suggests that a non-uniform bR 6 film was deposited, which causes scattering of the light [30].
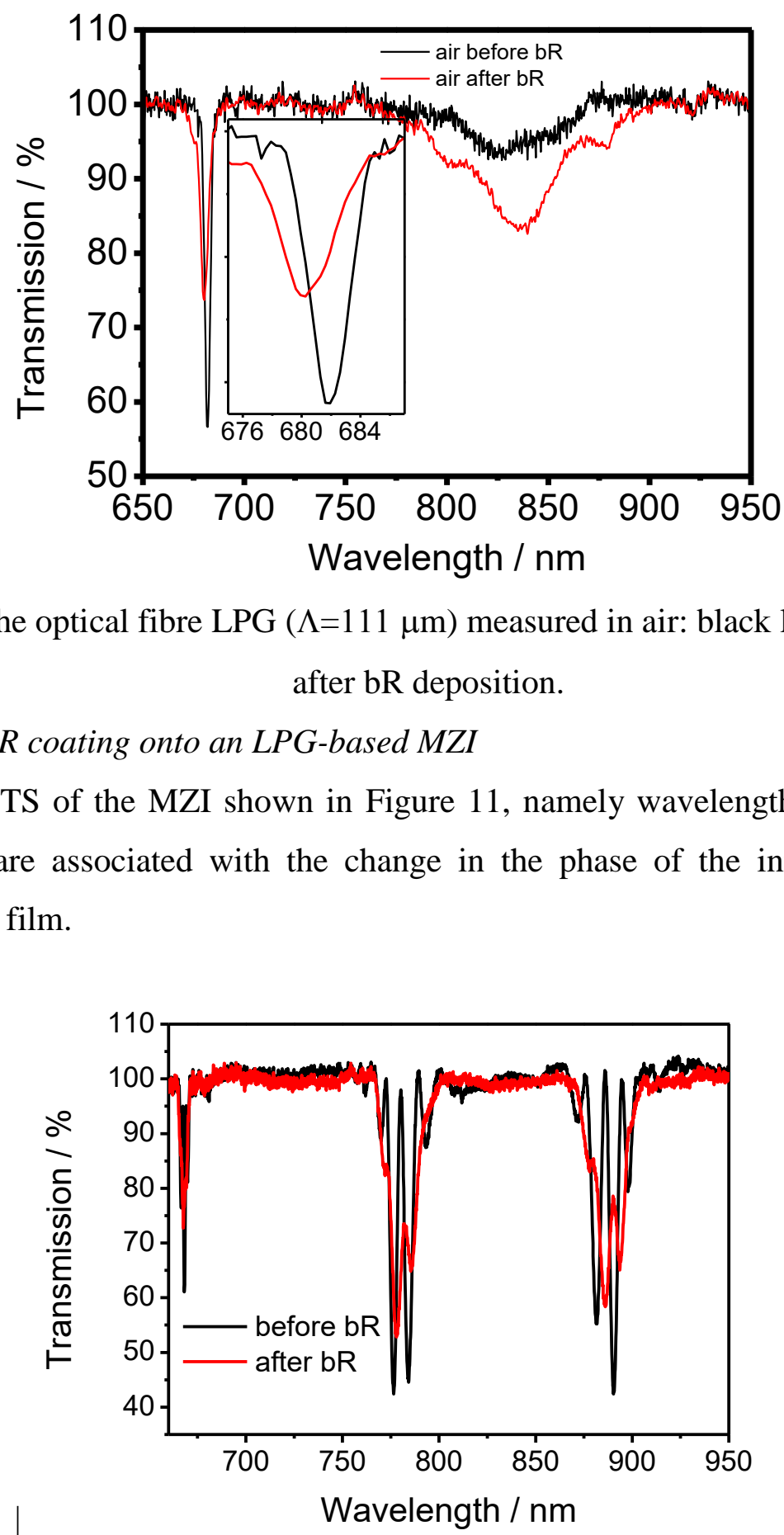

Figure 11. TS of the LPG based MZI $(\Lambda=110.3 \mu \mathrm{m}$, length of $3 \mathrm{~cm})$ measured in air before (black line) and after (red line) bR deposition. 
4 Figure 12 shows the photo-induced changes in the TS of an LPG (period $111 \mu \mathrm{m}$ ) modified with a $5 \quad(\mathrm{PDDA} / \mathrm{bR})_{12}$ film. A $0.1 \mathrm{~nm}$ wavelength shift of the $1^{\text {st }}$ resonance band was observed along with a $1.7 \%$ 6 change in attenuation at $840 \mathrm{~nm}$. As was shown in the case of an unmodified LPG immersed into a bR 7 solution, the efficiency depended strongly upon the number of photorefractive centres present on the 8 surface of the fibre and thus potentially could be improved by the deposition of the thicker bR films. It 9 might also be possible to optimise the film thickness to access the "mode transition region" [38], a coating thickness at which a mode of the waveguide formed by the coating is phase matched to a cladding mode, which causes the attenuation bands to become highly sensitive to the thickness of the coating.

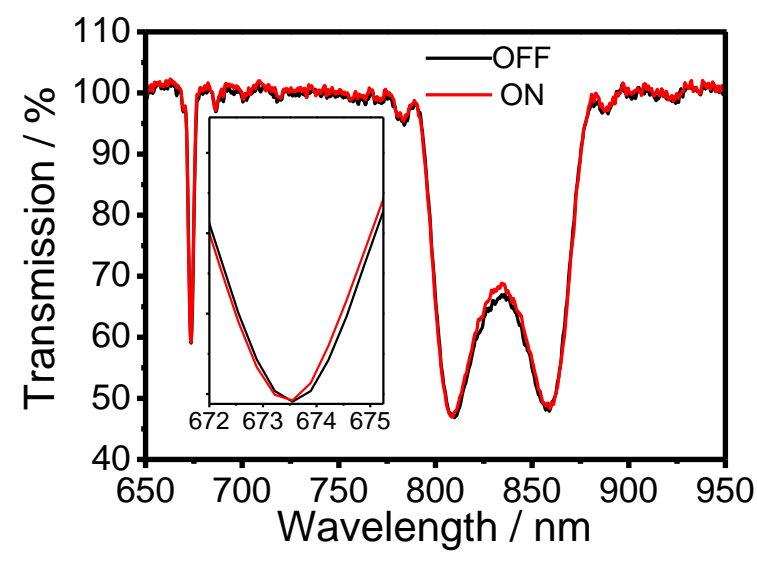

(a)

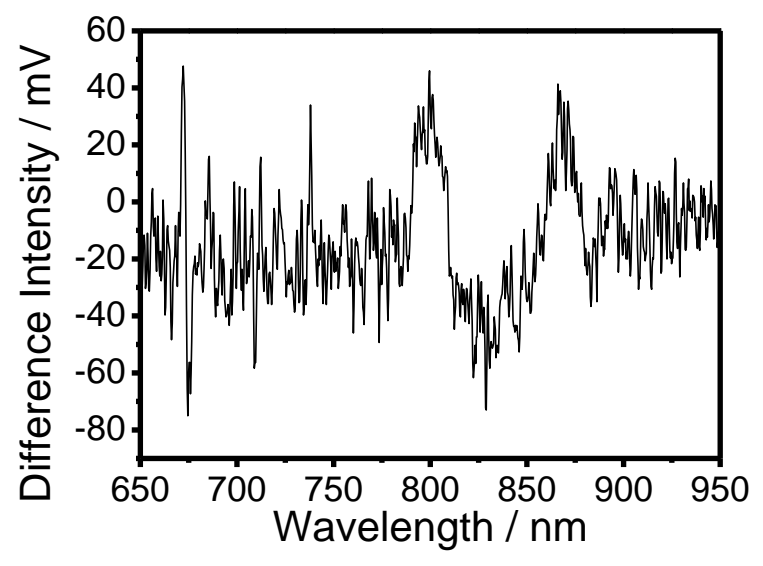

(b)

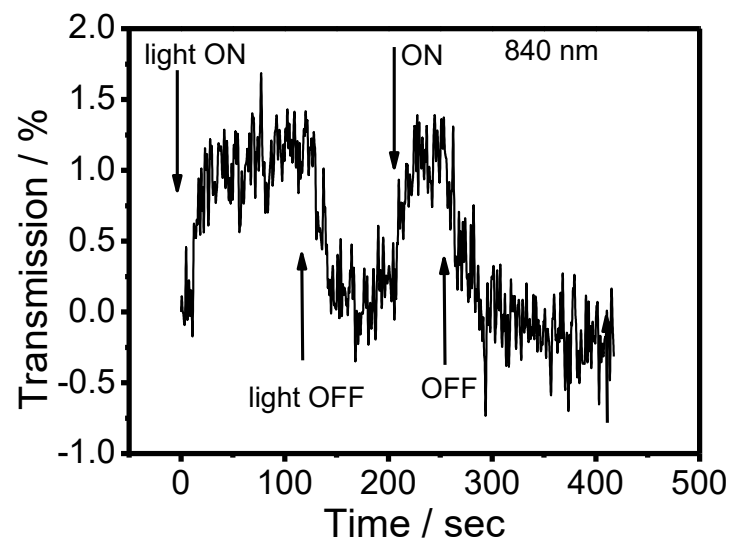

(c)

Figure 12. (a), TS of an LPG of period $110.9 \mu \mathrm{m}$ and modified with the LbL (bR/PDDA) 12 film measured before (black line) and during (red line) actinic light exposure; (b), the difference TS (obtained by subtracting the TS measured before exposure to the actinic light from that measured after 
1 the saturation point during exposure to the actinic light) and (c), dynamic intensity change measured at $834 \mathrm{~nm}$.

\section{$3 \quad$ 3.3.2 Cast bR film}

4 Similarly to the results observed when the LPG was immersed into a bR solution, when an LPG of period

$5 \quad 111 \mu \mathrm{m}$ that had been modified with the cast bR film was exposed to actinic light, a blue wavelength

6 shift of the $1^{\text {st }}$ band (ca. $0.13 \mathrm{~nm}$ ), accompanied by an increase of the attenuation of the second band (ca.

7 1\%) was observed, as shown in Figure 13. The amplitude of the change, however, was much smaller as

8 compared to that observed in the bR solution. On the other hand, the response and recovery times were

9 within seconds, that is ca. 10 times faster for LPGs modified with bR films, Figure 13b.

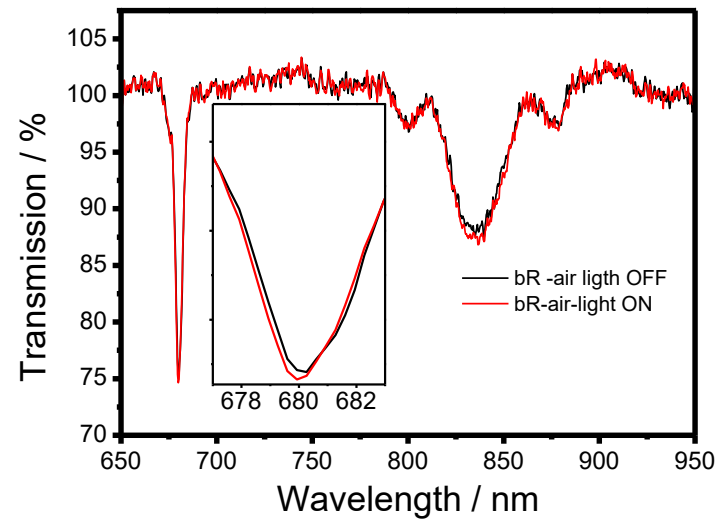

(a)

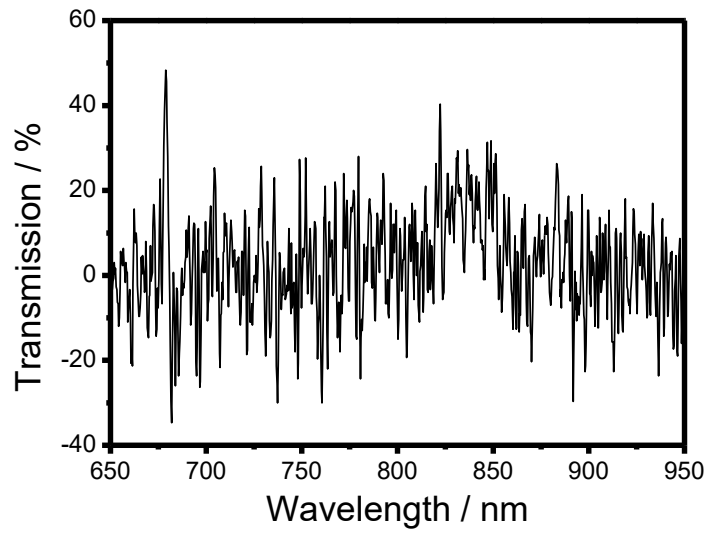

(b)

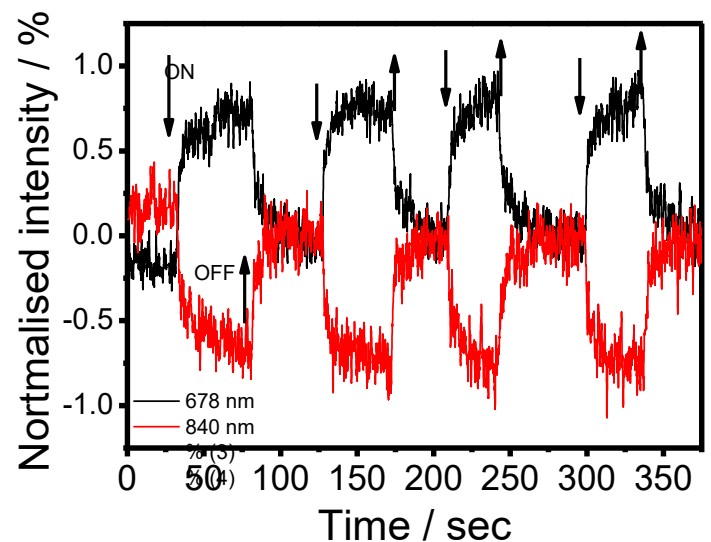

(c)

Figure 13. (a), TS of the LPG $(\Lambda=111 \mu \mathrm{m})$ modified with the casted bR film measured: black line, before and red line, after actinic light exposure; (b), difference TS (obtained by subtracting the TS measured before exposure to the actinic light from that measured after the saturation point during exposure to the actinic light) and (c), dynamic intensity change measured at: black line, $678 \mathrm{~nm}$; and red line, $840 \mathrm{~nm}$. 

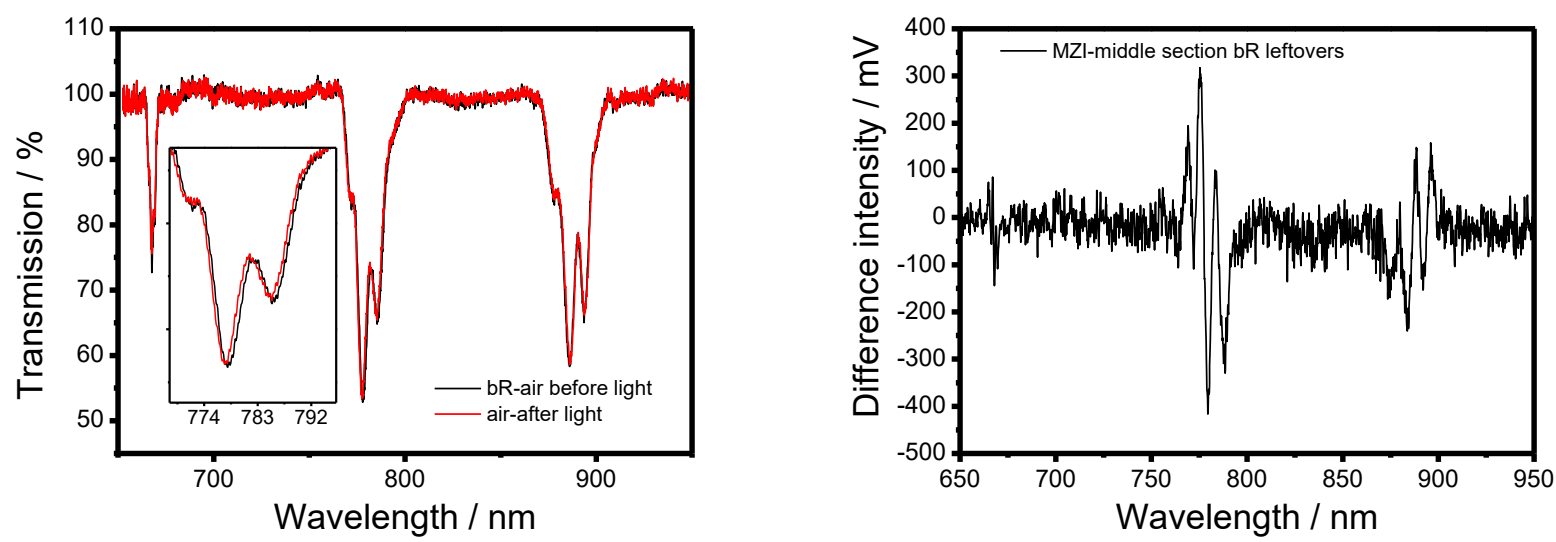

Figure 14. (a), TS of the MZI $(\Lambda=110.3 \mu \mathrm{m})$ where the section of fibre separating the LPGs was modified with the cast bR film measured before (black line) and during (red line), actinic light exposure; (b), difference TS (obtained by subtracting the TS measured before exposure to the actinic light from that measured after the saturation point during exposure to the actinic light) and

Table 1 summarizes performance of the all-optical switching obtained using the LPG and LPG-based MZI in devices immersed in the bR solution, and modified with LbL and casted films. The best performance in terms of switching time $(8 \pm 1 \mathrm{~s})$ was achieved using the LPG modified with casted film, while the highest efficiency $(32 \pm 2 \%)$ was achieved with the MZI immersed in a bR solution of concentration $12 \mathrm{mg} / \mathrm{mL}$. The switching times of bR depend on the protein concentration, film thickness, matrix composition and light intensity $[12,39]$. The values for cast film correspond well with the previously reported of $6.0 \pm 0.8 \mathrm{sec}$ [12]. The response time of the LbLfilm was twice that of cast thin film, most likely a result of the influence of the polycation on the bR-photocycle. It is known that amine containing compounds (such as the polycation PDDA used in depositing the LBL film) tend to slow the transition between ground state and M-intermediate [26]. 
Table 1: summary of the all-optical switching.

\begin{tabular}{|c|c|c|c|}
\hline Sample & Sensor & Switching time, sec & Efficiency, \% \\
\hline \multirow{2}{*}{ bR solution $^{\mathrm{a}}$} & LPG & $150 \pm 10^{\mathrm{b}}$ & $16 \pm 1^{\mathrm{b}}$ \\
\cline { 2 - 4 } & MZI & $200 \pm 20^{\mathrm{c}}$ & $32 \pm 2^{\mathrm{c}}$ \\
\hline \multirow{2}{*}{ LbL film } & LPG & $15 \pm 2^{\mathrm{d}}$ & $1.7 \pm 0.5^{\mathrm{d}}$ \\
\cline { 2 - 4 } & MZI & - & - \\
\hline \multirow{2}{*}{ Cast film } & LPG & $8 \pm 1^{\mathrm{e}}$ & $1 \pm 0.5^{\mathrm{e}}$ \\
\cline { 2 - 4 } & MZI & $9 \pm 1$ & $15 \pm 2$ \\
\hline
\end{tabular}

a $12 \mathrm{mg} / \mathrm{mL}$

${ }^{\mathrm{b}}$ at $840 \mathrm{~nm}$, Figure $5 \mathrm{c}$; errors standard deviation of 3 measurements;

${ }^{c}$ at $781 \mathrm{~nm}$, Figure $8 \mathrm{c}$; errors standard deviation of 3 measurements;

${ }^{d}$ at $840 \mathrm{~nm}$, Figure 12c; errors standard deviation of 3 measurements;

${ }^{\mathrm{e}}$ at $840 \mathrm{~nm}$, Figure 13c; errors standard deviation of 3 measurements;

Conclusions

All-optical switching using optical fibre LPGs modified with bacteriorhodopsin (bR) has been demonstrated. The switching wavelength is determined by the period of the LPG and thus can be tailored by choosing the appropriate grating period. The efficiency of the switching was $16 \pm 1$ and $32 \pm 2 \%$ for an LPG and an MZI immersed into a bR solution (12 mg/mL), respectively. The switching times observed for LPG coated with bR-films prepared by LbL and casting were within 8s, which is approximately 10 times faster than that observed for devices immersed in bR solutions, with a $1.7 \%$ signal modulation, Table 1. The main purpose of the current work is to demonstrate, for the first time, the principle of alloptical switching using LPG and bR-protein. Future work will focus on increasing the efficiency of the signal modulation by optimising the bR film thickness and by using chemically and genetically modified bR samples and also on decreasing the switching time [11]. bR-based configurations are known to achieve much faster switching times, which can be achieved using thin films and also when pulsed acitinic light source is used [13]. Also as demonstrated Fábián et al. [22] by using ultrafast BR->K and BR->I transitions ultrafast switching is possible. The switching wavelength can also be moved to infrared region (1310-1600 $\mathrm{nm}$ ) simply by changing grating period of the LPG or MZI devices to satisfy demands of the optical communication. bR-based optical components in the form of thin films are also have been extensively used for the development of the chemical sensors and their combination with LPG devices has a potential to expand their application in sensors. The switching time could be shortened considerably by using pulsed actinic light source [18].

Acknowledgments: The authors would like to acknowledge the support of a UK Engineering and 30 Physical Sciences Research Council Platform Grant (EP/H02252X/1) and responsive mode grants 31 (EP/L010437/1) and (EP/N025725/1). 
1 S. Boscolo and C. Finot, "Nonlinear pulse shaping in fibres for pulse generation and optical processing,” International Journal of Optics 2012, 59057 (2012).

2 A. S. Haque and J. Nelson, "Toward organic all-optical switching," Science 327, 1466 (2010).

3 H. Kageyama, H. Ohishi, M. Tanaka, Y. Ohmori, and Yasuhiko Shirota, "High performance organic photovoltaic devices using amorphous molecular materials with high charge-carrier drift mobilities," Appl. Phys. Lett. 94, 063304 (2009).

4 S. Gunes et al., "Charge carrier transporting molecular materials and their applications in devices," Chem. Rev. 107, 1324 (2007).

5 R. H. Friend, R. W. Gymer, A. B. Holmes, J. H. Burroughes, R. N. Marks, C. Taliani, D. D. C. Bradley, D. A. Dos Santos, J. L. BreÂdas, M. LoĖgdlund, and W. R. Salaneck, "Electroluminescence in conjugated polymers," Nature 397, 121-128 (1999).

6 K. M. Vaeth, “OLED-display technology,” Inform. Display 19, 12-17 (2003).

7 R. J. Williams, N. Jovanovic, G. D. Marshall, and M. J. Withford, “All-optical, actively Q-switched fiber laser," Optics Express 18, 7714-7723 (2010).

8 M. Imai, and S. Sato, "Optical switching devices using nonlinear fiber-optic grating coupler," Photonics Based on Wavelength Integration and Manipulation IPAP Books 2, 293-302 (2005)

9 Y. Lu, and X. Gu, "All-fiber passively Q-switched fiber laser with a Sm-doped fiber saturable absorber," Optics Express 21, 1997-2002 (2013).

10 J. K. Lanyi, Bacteriorhodopsin. Previously published in Biophysics Textbook Online, 2001.

11 N. Hampp, "Bacteriorhodopsin as a photochromic retinal protein for optical memories," Chemical Reviews 100, 1755-1776 (2000).

12 S.O. Korposh, Y.P. Sharkan, M.Y. Sichka, D.-H. Yang, S.-W. Lee, J.J. Ramsden, "Matrix influence on the optical response of composite bacteriorhodopsin films to ammonia", Sensors Actuators B 133(1) 281-290 (2008).

13 A. Dér, S. Valkai, A. Mathesz, I. Andó, E. K. Wolff, P. Ormos, "Protein-based all-optical sensor device," Sensors and Actuators B 151, 26-29 (2010).

14 H. Sasabe, T. Furuno, K. Takimoto, "Photovoltaics of photoactive protein/polypeptide LB films," Synthetic Metals 28, 787-792 (1989).

15 Q. W. Song, C. Zhang, R. Gross, R.R Birge, "Optical limiting by chemically enhanced bacteriorhodopsin films," Optics Letters 18, 775-777 (1993).

16 C.P. Singh, S. Roy, “All-optical logic gates with bacteriorhodopsin” Current Applied Physics 3, 163-169 (2003). 
17 R. Sukhdev, M. Prasad, J. Topolancik, and F. Vollmer, "All-optical switching with bacteriorhodopsin protein coated microcavities and its application to low power computing circuits," J. Appl. Phys. 107, 053115 (2010).

18 L. Fábián, E. K. Wolff, L. Oroszi, P. Ormos, and A. Dér, "Fast integrated optical switching by the protein bacteriorhodopsin," Appl. Phys. Lett. 97, 023305 (2010).

19 P. Ormos, L. Fábián, L. Oroszi, E. K. Wolff, J. J. Ramsden, and A. Dér, "Protein-based integrated optical switching and modulation,” Appl. Phys. Lett. 80, 4060-4062 (2002).

20 A. Dér, S. Valkai, L. Fábián, P. Ormos, J. J. Ramsden, and Elmar K. Wolff, "Integrated optical switching based on the protein bacteriorhodopsin," Photochem Photobiol. 83, 393-396 (2007).

21 A. Mathesz, L. Fábián, S. Valkai, D. Alexandre,P. V.S. Marques, P. Ormos, E. K. Wolff, and A. Dér, "High-speed integrated optical logic based on the protein bacteriorhodopsin," Biosens Bioelectron. 46, 48-52 (2013).

22 L. Fábián, Z. Heiner, M. Mero, M. Kiss, E. K. Wolff, P. Ormos, K. Osvay, and A. Dér, "Proteinbased ultrafast photonic switching," Opt. Expr. 19, 18861-18870 (2011).

23 D. Zeisel and N. Hampp, "Spectral relationship of light-induced refractive index and absorption changes in bacteriorhodopsin films containing wildtype BRm and the variant BRMN," J. Phys. Chem. 96, 7788-7792 (1992).

24 M. H. Griep, K. A. Walczak, E. M. Winder, D. R. Lueking, C. R. Friedrich, "Quantum dot enhancement of bacteriorhodopsin-based electrodes," Biosensors and Bioelectronics 25(6), 1493-1497 (2010).

25 Z. Zhao, P. Wang, X. Xu, M. Sheves, and Y. Jin, "Bacteriorhodopsin/Ag nanoparticle-based hybrid nano-bio electrocatalyst for efficient and robust $\mathrm{H} 2$ evolution from water," Journal of the American Chemical Society 137 (8), 2840-2843 (2015).

26 Z. Batori-Tartsi, K. Ludmann, "Chemically modified bacteriorhodopsin based photosensitive material for optoelectronic application,” in: A. De' r, L. Keszthelyi (Eds.), Bioelectronic Applications of Photochromic Pigments, IOS Press, Amsterdam, 2001, pp. 137-148.

27 D. Oesterhelt, W. Stoeckenius, "Functions of a new photoreceptor membrane," Proc. Natl. Acad. Sci. USA 70, pp. 2853-2857 (1973).

28 A. Kikineshy, Z. Bathori-Tarczy and Y. Sharkany, In: W.K. Jones, G. Harsanyi (eds) Multichip Modules with Integrated Sensors. NATO ASI Series 3, High Technology. Dordrecht: Kluwer, 1996, pp. 181-184.

29 S. Korposh, T. Wang, S. James, R. Tatam and S.-W. Lee, "Pronounced aromatic carboxylic acid detection using a layer-by-layer mesoporous coating on optical fibre long period grating," Sensors and Actuators B: Chemical 173, 300-309 (2012).

30 S. Korposh, W. Batty, S. Kodaira, S.-W. Lee, S.W. James, S.M. Topliss, R.P. Tatam, ”Ammonia sensing using a fibre optic long period grating with a porous nanostructured coating formed from silica nanospheres," Proc. SPIE 7653, 76531D-1 (2010). 
31 S. Korposh, S.W. James, R.P. Tatam, S.-W. Lee, "Refractive index sensitivity of fibre optic long period gratings coated with $\mathrm{SiO} 2$ nanoparticle mesoporous thin films," Meas. Sci. Tech. 22, 075208s (2011).

32 S. Korposh, R. Selyanchyn, W. Yasukochi, S.-W. Lee, S. James, R. Tatam, “Optical fibre long period grating with a nanoporous coating formed from silica nanoparticles for ammonia sensing in water," Materials Chemistry and Physics 133, 784- 792 (2012).

33 B. H. Lee and J. Nishii, "Bending sensitivity of in-series long-period gratings," Opt. Lett. 23, 16241626, (1998).

34 R.Y.N Wong, E. Chehura, S. E. Staines, S. W. James and Ralph P. Tatam, "Fabrication of fiber optic long period gratings operating at the phase matching turning point using an ultraviolet laser," Appl. Opt. B, 4669-4674 (2014).

35 S.C. Cheung, S.M. Topliss, S.W. James and R.P. Tatam, "Response of fibre optic long period gratings operating near the phase matching turning point to the deposition of nanostructured coatings", Journal of the Optical Society of America B, 25, 902 (2008).

36 J.-A. He, L. Samuelson, L. Li, J. Kumar, and S. K. Tripathy, "Oriented

Bacteriorhodopsin/Polycation Multilayers by Electrostatic Layer-by-Layer Assembly, Langmuir 14, 1674-1679 1998.

37 S. Korposh, R. Wong, S.W. James, R.P. Tatam "Temperature and thermo-optic coefficient measurements using optical fibre long period gratings operating at phase matching turning point", Proc. SPIE 8794, 87942N(4) (2013).

38 I. Del Villar, I. Matías, F. Arregui, and P. Lalanne, "Optimization of sensitivity in Long Period Fiber Gratings with overlay deposition,” Opt. Express 13(1), 56-69 (2005).

39 J.-A. He, L. Samuelson, L. Li, J. Kumar, and S. K. Tripathy, "Photoelectric properties of oriented bacteriorhodopsin/polycation multilayers by electrostatic layer-by-layer assembly," The Journal of Physical Chemistry B. 02 (36), 7067-7072 (1998). 